\title{
Entrevista com o Professor François Vellas, Ph.D.
}

\author{
Interview with Professor François Vellas, Ph.d.
}

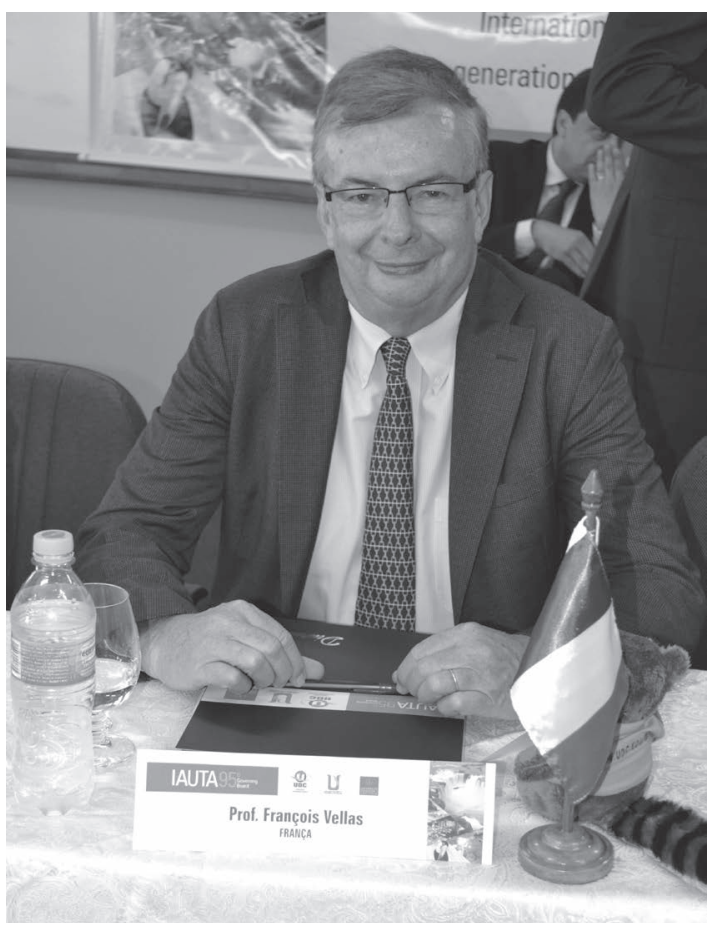

Professor François Vellasé, atualmente, a pessoa mais influente entre os gestores das Universidades da Terceira Idade de todo o mundo, sendo a principal referência para os novos programas que se multiplicam por todos os continentes. É professor de Economia do Turismo Internacional na Universidade de Toulouse 1 e tem vasta experiência em consultorias nas Nações Unidas da União Europeia, UNESCO, Banco Mundial e muitas organizações mundiais de relevo. Além de atuar como professor, pesquisador, extensionista e consultor em diversas agências, tem dedicado grande parte de seu tempo para presidir a AIUTA - International Association of Universities of the Third Age, que orienta os programas Universidade da Terceira Idade em todo o mundo.

Entrevistador: Adriano da Silva Rozendo ${ }^{1}$

$\mathrm{Na}$ atualidade, são comuns os programas de Universidades Abertas à Terceira Idade no Brasil. Segundo Veras e Caldas, tais programas chegaram ao Brasil na década de 1980. Na década de 1990, principalmente após a promulgação da Política Nacional do Idoso, de 1994, foram se convertendo em políticas públicas de massa, em conjunto com ações de extensão universitária de universidades públicas e privadas. Apesar de bastante expandidas e bem conhecidas no cenário nacional, tais ações foram principiadas na França, na Universidade de Toulouse, em 1973. Naquele ano, o professor de Direito Internacional Pierre Vellas, norteado por experiências e desafios de promoção de direitos humanos em suas andanças pelo mundo, resolveu criar a Universidade da Terceira Idade (U3I), em parceria com colegas e orientandos de pós-graduação. Em poucas décadas, a U3I iria se estabelecer em todo o mundo civilizado. Hoje em dia, somente na China, são cerca de 60 mil programas em funcionamento.

Universidade Federal de Mato Grosso. Núcleo de estudos e atividades da Terceira Idade. Rondonópolis, MT, Brasil.

Correspondência / Correspondence

Adriano da Silva Rozendo

UFMT/NEATI

Av. Governador Júlio de Campus, s/n

78735-901 Rondonópolis-MT, Brasil

E-mail: rozendoadriano@aol.com 
2014 foi um ano especial para a AIUTA, que entre os dias 02 e 04 de junho comemorou seu quadragésimo aniversário em uma grande conferência que contou com a participação de conselheiros, membros e convidados de todo o mundo. O evento foi realizado na Universidade de Toulouse 1, onde, além da história da Associação, foram apresentados trabalhos de grande relevo científico, por professores, pesquisadores e coordenadores de programas de todos os continentes. Já a última conferência da Associação foi realizada na cidade de Foz do Iguaçu-PR, entre os dias 13 e 14 de novembro de 2014, intitulada "Cooperação Internacional e Universidade da Terceira Idade".

A entrevista a seguir foi feita após a conferência de Toulouse, com o presidente da AIUTA, professor Pierre Vellas, filho do fundador da U3I. Trata-se de uma conversa na qual se buscou traçar um pouco da história das U3Is, seus rumos e expectativas futuras pelo ponto de vista de seus pioneiros. O material é de interesse daqueles que estudam e participam das U3Is e traz relatos inéditos para a literatura.

1. Quando seu pai, professor Pierre Vellas, começou a U3I na Universidade de Toulouse, qual era seu intuito?

Naquele tempo, era o fim de 30 anos de um boom de crescimento econômico e as pessoas estavam pensando em realizações mais intelectuais e menos consumistas. No começo, não se tratava especificamente de um programa voltado para pessoas idosas, mas sim, para aposentados que procuravam algo novo para fazer. Eles não queriam ficar em casa esperando pela morte, e alguns voluntários queriam fazer alguma coisa. Naquele mesmo período, professor Pierre Vellas estava pensando que as universidades não estavam muito integradas à sociedade. Era um lugar para estudar, um lugar para pesquisa acadêmica, mas um pouco apartado dos problemas das cidades. Então, o professor Pierre Vellas tentou agregar estes dois aspectos para tentar ofertar o que a nova geração de idosos necessitava, assim como procurar possibilidades de abrir a universidade para a sociedade. Este foi o começo da U3I.

\section{Então, no começo, a U3I era algo parecido com a Campus Community dos Estados Unidos?}

Bem, na verdade não, porque se tratava mais de um vínculo entre aposentados e idosos e a universidade, mas não para ficar o dia todo, a semana toda, ou longos períodos, mas para participar de algum curso ou alguma atividade na universidade.

\section{Professor Pierre Vellas lecionava na Universidade de Toulouse, na área de Ciências Humanas?}

Ele era diretor do Instituto de Direito e especialista em Direito Internacional. Ele estava, por muitos anos, fazendo andanças em países subdesenvolvidos. Então, ao longo de sua carreira, ficou às voltas com alguns problemas sociais, como ilegalidade, pobreza, etc. Após muitas experiências na maioria dos países da África, Ásia e América do Sul, ele estava se dedicando a pensar sobre o que fazer com aquelas pessoas que não estavam totalmente integradas à sociedade, fosse por pobreza, por desemprego, etc. Acho que foi este o pano de fundo que levou até o caminho da U3I. A partir dessas experiências, quando ele se deparou com o problema dos aposentados na França, ele fez um link com as experiências de trabalho com a pobreza fora da Europa, assim como com o novo problema da sociedade que estava em nosso país e em nossa cidade.

4. Talvez quando o senhor costumava conversar com seu pai, ele tenha comentado sobre alguma experiência com grupos de idosos que ele tivesse observado pelo mundo durante suas viagens e que ele tivera-se inspirado antes de criar a U3I?

Acho que não. Ele teve a ideia por ele mesmo. Um dos aspectos importantes foi que seus próprios pais estavam aposentados e não tinham nada para fazer. Então ele estava pensando: “o 
que eu posso fazer não especificamente por eles, mas para a geração deles"? Algum dia ele deve ter tido a ideia, talvez a tenha tido muito antes de implantá-la. O fato foi que ele teve a ideia das U3I e, mais adiante, devido ao seu cargo respeitável dentro da Universidade de Toulouse, ele pôde encontrar os meios para realizar o programa.

5. O senhor quer dizer que o professor Pierre Vellas teve apoio da Universidade de Toulouse para implantar a U3I?

Ele teve apoio depois de já ter iniciado o programa. A iniciativa veio primeiro, por meio da organização de algumas conferências para idosos e a utilização das salas da universidade. A partir de então, com o sucesso da ação, pode-se dizer que ele obteve apoio da universidade.

6. No começo o professor Pierre Vellas coordenava o programa ofertando quais tipos de atividades?

Ele começou a partir da união da cooperação internacional em Toulouse. Isso significa que a U3I começou a partir de uma equipe internacional. No começo, a equipe era composta por pessoas de muitas nacionalidades, especialmente por alunos de pós-graduação. Muitos estudantes de doutorado estavam engajados na implantação da U3I. Os idosos participavam de conferências sobre muitos assuntos, sobre diversas experiências e realidades do mundo todo. Para eles tudo aquilo era muito novo, porque se tratava de uma nova experiência para os aposentados. A ideia era abrir a universidade não apenas para as pessoas da academia, mas para todas as pessoas, incluindo os novos estudantes da U3I. Para eles, era um sonho fazer aquilo, porque aqueles idosos não puderam frequentar a universidade quando eram jovens. Eles costumavam dizer: "Nós nunca pudemos fazer isso antes". Então a U3I, no seu começo, era um sonho que se tornava realidade. As principais atividades eram conferências e seminários, em arte, literatura e relações internacionais, nas quais se abordavam problemas de todo o mundo, como paz internacional, objetivos a serem alcançados na área da saúde, etc.

7. O senhor acha que o fato de muitas pessoas de diversas nacionalidades envolvidas na idealização e implantação da U3I colaborou para o crescimento do programa ao redor do mundo de forma tão rápida?

Acho que, desde o começo, a U3I não era algo local, era algo que tinha que se abrir, não apenas em Toulouse, mas internacionalmente. Era uma proposta internacional; um tipo de sonho para muitos idosos e pessoas aposentadas. Então, a U3I significa possibilidade para essas pessoas frequentarem a universidade, assim como uma nova possibilidade para algumas pessoas que não tiveram oportunidade de viajar para conhecer outros países. Esta iniciativa era internacional desde o começo; foi uma iniciativa de alunos e professores da América Latina, África e Ásia também. Tratava-se de uma possibilidade de ofertar diversas atividades para a comunidade local, e depois para pessoas de todo o mundo.

\section{Quando as U3Is passaram a serimplantadas em outros países?}

Este é um ponto importante, porque a U3I começou entre 1973 e 1974, e em 1975 e 1976 já estava presente na Suíça, na Bélgica, na Itália e no Canadá. Estes foram os principais países a difundir o programa. Eram países dos quais o professor Pierre Vellas era muito próximo. Havia focos em cada um destes países, em universidades em Neuchâtel; Genebra; Zurique e Lausanne, na Suíça. Na Bélgica existia um vínculo muito forte com Namur. No Canadá, era em Cherbourg e Quebec, inicialmente, e depois em outras cidades. Então, no início, a U3I foi se expandindo devido a contatos pessoais do professor Pierre Vellas, mas esses contatos foram se expandindo para outros países.

9. No Brasil, é muito comum ouvir que os primeiros gerontologistas do país foram formados na França e, por isso, trouxeram daqui os modelos de gerontologia e de U3I. Nas conversas sobre as trajetórias das U3Is no Brasil, ouvimos histórias de fundadores de programas U3I no Brasil que haviam acabado de regressar de estudos de pósgraduação na França ou na Bélgica. O senhor sabe se a AIUTA tem algum registro documental sobre esses fatos? 
Temos os arquivos desde o início da AIUTA, que foi inaugurada aproximadamente dois anos após o início da U3I. Mas os documentos estavam arquivados em Paris anteriormente. Hoje os documentos se encontram em Toulouse. Tratase de um excepcional montante de documentos históricos do movimento internacional da U3I, atualmente aberto para pesquisadores. Tenho certeza de que existem registros muito úteis para encontrar informações sobre o movimento das U3Is no Brasil também.

\section{0. É também muito comum ouvir que mesmo} os termos "terceira idade" foram criados em Toulouse junto com a U3I. O senhor acredita que esta informação é verídica?

Sim, o termo "terceira idade" está vinculado com o movimento das U3Is. Mas "terceira idade" é um termo não muito otimista. Talvez seja necessário revisarmos esta nomenclatura, talvez seja melhor termos como "Universidade para Idosos". $\mathrm{Na}$ França, o termo "terceira idade" soa bem, mas em alguns países, não. Acho que "Universidade para Idosos" se enquadraria melhor no perfil internacional. Outro aspecto relevante das nomenclaturas com o qual é necessário tomar cuidado é que, em alguns países, incluindo a França, iniciativas são baseadas no conceito de Universidade Aberta para todos, incluindo idosos. É necessário ressaltar este aspecto para não haver enganos. Usualmente, a Universidade Aberta tem foco para capacitação de recursos humanos e busca inserir os frequentadores no mercado de trabalho ou em atividades de geração de renda. Este não é o caso da U3I clássica, que tem como objetivo ajudar o idoso nos aspectos intelectuais, mas não de capacitação de recursos humanos para integração, ou reintegração ao mercado.

\section{Professor Vellas, qual são os principais objetivos da AIUTA nos dias atuais?}

O principal objetivo atual é tentar encontrar uma resposta para o envelhecimento demográfico, o aumento da população idosa em todo o mundo. Na Europa e em outros países, entre 1945 e 1955 houve o chamado "baby boom", que significa o fenômeno das grandes taxas de natalidade. Agora essas crianças estão idosas, então temos um tipo de boom do idoso e, por isso, um dos objetivos da AIUTA é encontrar novos caminhos para obter respostas relevantes para essa grande população de idosos. Este fenômeno demográfico acontece na Europa, mas também em muitos outros países. $\mathrm{Na}$ África, Ásia e, é claro, na América do Norte, América Latina e América do Sul, igualmente. Então precisamos desenvolver um novo programa de pesquisa para buscarmos o que pode ser feito do ponto de vista da U3I, para encontrarmos soluções relevantes para este quantitativo de população idosa. Em geral, observa-se que as U3Is continuam realizando as mesmas atividades do passado, e isso não é o suficiente. Temos que inovar em termos de educação, talvez com as novas tecnologias de comunicação em educação. Além disso, temos que inovar a relação entre universidade e idoso. Como a U3I pode alcançar o idoso residente em cidades pequenas, por exemplo? Temos que perseguir novos objetivos nas U3Is, e isso significa abrir o programa em áreas da educação, assim como lazer, atividades físicas e esportes. É necessário abrir novos links com nossos colegas dos cursos de Medicina e outras áreas que pouco atuam nos programas. Temos que buscar caminhos para promover a participação do idoso, não apenas como frequentador das U3Is, mas como profissionais das U3Is, compartilhando experiências de muitos idosos que podem se unir às equipes de execução dos programas. Poderíamos tentar misturar equipes de jovens com idade em torno de 25 anos com idosos. Este é um caminho para tomar proveito das experiências dos idosos.

12. Para encerrarmos, que tipo de atividades inovadoras a equipe da U3I da Universidade de Toulouse tem realizado ultimamente?

Posso dar dois exemplos de novas atividades. A primeira são as aulas de redes sociais na internet, para tentar adicionar mais idosos nestes tipos de redes, como o Facebook e o Whats $A p p$, pois é muito importante estar em contato com as novas gerações. O segundo exemplo é resultado do trabalho de um grupo de pesquisa, uma experiência de pesquisa entre a U3I em Toulouse e a U3I de Namur, na Bélgica. 
A abordagem é sobre a situação de idosos prisioneiros do sistema carcerário. Nas prisões existem alguns idosos, evidentemente por terem feito algo de muito ruim no passado, mas o fato é que para esse idoso ninguém olha. Tínhamos alguns advogados aposentados frequentando ambas U3Is e desenvolvemos um tipo de programa. Estamos procurando respostas para o que poderíamos fazer por essas pessoas, de um ponto de vista social. Então, em parceria com a U3I de Namur, estamos realizando esse trabalho. Nossas inovações buscam também alcançar estes idosos que querem estar prontos para um novo mundo.

\section{REFERÊNCIAS}

1. Veras, RP, Caldas CP. Promovendo a saúde e a cidadania do idoso: o movimento das universidades da terceira idade. Ciência \& Saúde Coletiva 2004; 9 (2):423 - 432. 